\title{
TORQUE RIPPLE MINIMIZATION OF A THREE PHASE MATRIX CONVERTER FED BLDC MOTOR
}

\author{
E.J.Niranjana Devi ${ }^{1}$, P.Subha Karuvelam ${ }^{2}$ \\ PG Scholar, Department of Electrical Engineering, GCE, Tirunelveli, India ${ }^{1}$ \\ Assistant Professor, Department of Electrical Engineering, GCE, Tirunelveli, India ${ }^{2}$
}

\begin{abstract}
The Matrix Converter (MC) is capable of synthesizing variable magnitude and frequency output voltage while maintaining desired input power factor and it eliminates the need for DC link capacitors. This has led to the broad classification of matrix converters as indirect matrix converter (IMC) on the presence of a DC link and Direct MC(DMC) based on the absence of a DC link. In this paper, a three phase IMC is used to drive the three phase BLDC motor, which consists of a Current Source Rectifier (CSR) and a Voltage Source Inverter(VSI) connected via a fictitious DC link. Space-vector modulation is used to generate the gate pulses for the CSR and the gate pulses for the VSI are generated based on the rotor position of the BLDC rotor. The PI speed controller is used hereto improve the speed response of the motor and a PI current controller is used to minimize the torque ripples. The IMC fed BLDC motor is simulated using Matlab software package and the results of open loop and closed loop systems are compared and validated.
\end{abstract}

Keywords: Indirect matrix converter (IMC), Permanent magnet Brushless DC Motor, PI Controller, Current source rectifier(CSR), Voltage source inverter(VSI), Space Vector PWM(SVPWM).

\section{INTRODUCTION}

Permanent magnet brushless DC (BLDC) motor is increasingly used in automotive, industrial, and household products because of its high efficiency, high torque and lower maintenance $[1,2]$. A BLDC motor is designed to develop the trapezoidal back EMF with square wave currents to generate the constant torque. Three hall position sensors are used to determine the position of the rotor, each are displaced by 120 electrical degree[3-6]. Since $180^{\circ}$ magnetic arc rotor is used here, the two phase conduction mode is preferred.

BLDC motors are traditionally driven by Pulse Width Modulated Voltage Source Inverters (PWM-VSI). However it has certain disadvantages like need of additional filter elements at input and output side, the poor quality of output waveforms and harmonics. The harmonics mainly depends on stability of DC link voltage. Compared with these conventional converters, matrix converters has the most desirable features of sinusoidal input current, regeneration capability, generation of load voltage with arbitrary amplitude and frequency $[9,10]$.Fig.1. shows the general block diagram of matrix converter fed BLDC motor.

In this paper, a BLDC motor is fed by a three-phase indirect matrix converter (IMC)and the IMC is constructed from 18 back-to-back IGBT switches which drives the BLDC motor .The IMC is considered as a CSR and a VSI connected via a fictitious DC link. The switching algorithm for CSR is based on space-vector modulation (SVM) [11].SVM allows direct control of input current and hence the harmonic contentsare reduced. The inverter gate signals are generated by decoding the halleffect signals of the BLDC motor and the three-phase output of the converter are given to the stator windings of BLDC motor.

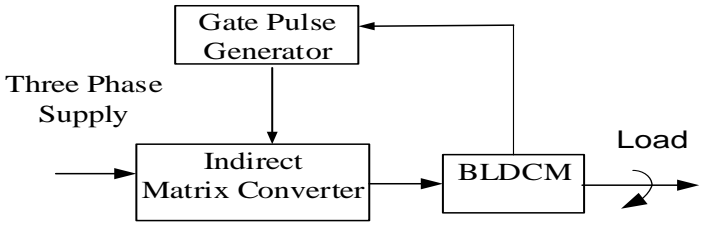

Fig.1. Block Diagram of Matrix Converter Fed BLDC Motor

In this paper, a control strategy using a PI speed and current control unit is proposed, designed and compared with the open loop system. The proposed control system guarantees the BLDC motor driven at the set speed, over the entire operating range and reduced torque ripples, while maintaining the three phase source side requirements like sinusoidal current, improved displacement factor etc.IMC fed BLDC motor drive is implemented in Matlab/ Simulink and simulation results were presented.

Next to the introduction part, the rest of the paper is organized as follows. Section II deals with the Matrix converter types and its switching strategy.Section III presents fundamentals and switching of BLDC motor.Section IV describes the MC fed BLDCM in open loop. Section V outlines the PI speed and current control scheme as used in the Matrix converter and the results and discussions are presented. Comparative analysis between open loop and closed loop system is discussed in Section VI.Finally conclusions are summarizedand presented in section VII.

\section{Matrix Converter (MC)}

Matrix Converter has an array of $m \times n$ bidirectional switches directly connect a " $m$ " input phases to " $n$ " output phases with variable magnitude and frequency output 
voltage.Matrix converters have the capability ofpower regeneration and suppression of input current harmonics, hence they areidentified as optimum drives for applications ranging from cranes, elevators and centrifugal pumps, to air-conditioning fans and feed-water pumps.Basic topologies of $\mathrm{MC}$ are direct matrix converter(DMC), indirect matrix converter(IMC) and sparse matrix converter.

\section{A. $\quad$ Direct Matrix Converter(DMC)}

The basic configuration of three phase to three phase direct matrix converter was introduced by Venturini in 1980 [13]. It consists of nine bidirectional switches that connect each output phase to each input phase which is capable of conducting currents and blocking voltages of both polarities, depending on control signal [15].

\section{B. $\quad$ Indirect Matrix Converter}

An IMC topology without a DC link capacitor was suggested by ziogas in 1986 [16] and analyzed in detail by Kim et al in 1998 [17].The IMC features a two stage power conversion with a unipolar current source input stage with six bidirectional switches(CSR) and a voltage source converter output stage(VSI)which is shown in Fig.2[14].

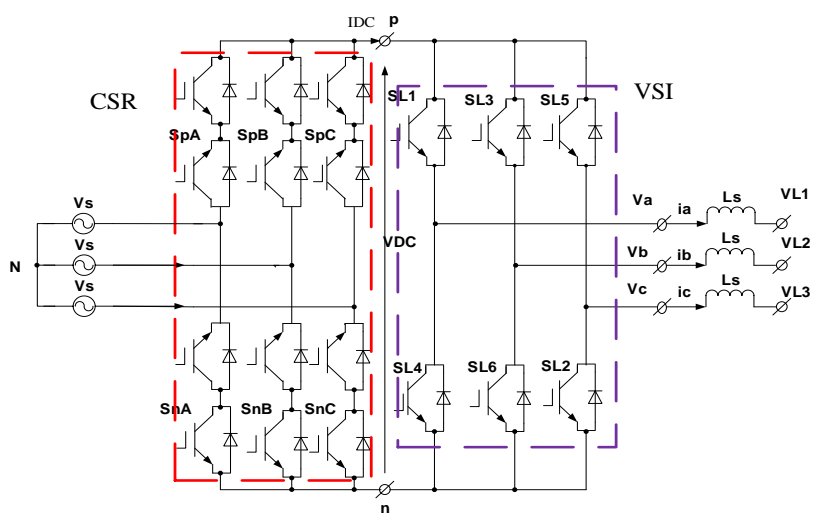

Fig.2. Indirect Matrix Converter

The DC side voltage should be positive for all time to ensure proper operation of this converter. The main objective of the CSR is to maintain pure sinusoidal input current waveforms as well as maintain positive voltage on the DC side. Assuming a stiff voltage source as the input and stiff current sink as the output, the DC side voltage is essentially decided by the switching functions of the rectifier and the input voltage and the DC side current is determined by the combination of output switching functions and output current.

\section{Space Vector Modulation for IMC}

The MC modulation methods are developed by Venturini and Alesina in 1980 which is referred to as the "direct modulation method ".A different types of modulation was introduced by Rodriguez in 1983 based on "fictitious DC link". The SVM was applied for MC by Huber and Boroyevich in 1989 [15].The SVM for IMC was developed by Huber in 1995 [11].In the SVM, the rectification stage is considered as the standalone
CSR.Due to the inductive nature of the load, the input current $i_{p}$ is assumed constant for each switching period. Hence the load of the rectifier is assumed to be constant DC current sink with the current $i_{p}=I_{D C}$. At any instant, the input lines should never be short circuited which results,

$$
S_{k A}+S_{k B}+S_{k C}=1, \quad k \in\{p, n\}(1)
$$

Where $S_{k A}, S_{k B}$ and $S_{k C}$ are the switching function of bidirectional switches. The rectifier should not only generate the DC link voltage but also has to maintain the sinusoidal and balanced input current with controllable displacement angle with respect to the input voltage.

In SVM, the input current is transformed into six distinctive input space vectors as shown in Fig.3. The magnitude of these current vectors depends on the instantaneous value of the current $i_{p}$. The switching combination for the CSR is shown in Table 1.

Each current vector shows the connection of input phases with the DC link. The current vector $I_{3}$ represents that the input phase $B$ is connected with the $p$ terminal and the input phase $A$ is connected with the $n$ terminal of the DC link. The switches $\mathrm{S}_{\mathrm{pB}}$ and $\mathrm{S}_{\mathrm{nA}}$ are $\mathrm{ON}$ at this instant. To maintain the displacement factor, the input currents have to be synchronized with the input voltages.

TABLE 1

SWITCHING COMBINATION FOR THE CSR

\begin{tabular}{|c|c|c|c|c|c|c|c|c|c|c|c|}
\hline \multicolumn{6}{|c|}{ Switching State } & \multicolumn{3}{|c|}{$\begin{array}{c}\text { Output } \\
\text { voltages }\end{array}$} & \multicolumn{3}{|c|}{$\begin{array}{l}\text { Input } \\
\text { currents }\end{array}$} \\
\hline$S_{p}$ & $\mathrm{~S}_{\mathrm{pB}}$ & $\mathbf{S}_{\mathrm{p}}$ & $S_{n}$ & $S_{n}$ & $S_{n}$ & $\mathbf{V}_{\mathbf{p}}$ & $\mathbf{V}_{\mathbf{n}}$ & $\mathbf{V}_{\mathrm{pn}}$ & $\overline{\mathbf{i}_{\mathrm{A}}}$ & $\overline{\mathbf{i}_{\mathbf{B}}}$ & $\mathbf{i}_{\mathbf{C}}$ \\
\hline $\begin{array}{l}\mathrm{A} \\
1\end{array}$ & 0 & $\begin{array}{l}\mathrm{C} \\
0\end{array}$ & $\frac{\mathbf{A}}{0}$ & 0 & $\frac{c}{1}$ & $\mathrm{~V}_{\mathrm{A}}$ & $\mathrm{v}_{\mathrm{C}}$ & $\mathrm{V}_{\mathrm{AC}}$ & $\mathrm{i}_{\mathrm{p}}$ & 0 & $-i_{p}$ \\
\hline 0 & 1 & 0 & 0 & 0 & 1 & $\mathrm{~V}_{\mathrm{B}}$ & $\mathrm{V}_{\mathrm{C}}$ & $\mathrm{V}_{\mathrm{BC}}$ & 0 & $\mathrm{i}_{\mathrm{p}}$ & $-\mathrm{i}_{\mathrm{p}}$ \\
\hline 0 & 1 & 0 & 1 & 0 & 0 & $\mathrm{~V}_{\mathrm{B}}$ & $\mathrm{V}_{\mathrm{A}}$ & $\mathrm{V}_{\mathrm{BA}}$ & $-\mathrm{i}_{\mathrm{p}}$ & $\mathrm{i}_{\mathrm{p}}$ & 0 \\
\hline 0 & 0 & 1 & 1 & 0 & $\overline{0}$ & $\mathrm{~V}_{\mathrm{C}}$ & $\mathrm{V}_{\mathrm{A}}$ & $\mathrm{V}_{\mathrm{CA}}$ & $-i_{p}$ & 0 & $\overline{i_{p}}$ \\
\hline 0 & 0 & 1 & 0 & 1 & 0 & $\mathrm{~V}_{\mathrm{C}}$ & $V_{B}$ & $\mathrm{~V}_{\mathrm{CB}}$ & 0 & $-\mathrm{i}_{\mathrm{p}}$ & $i_{p}$ \\
\hline 1 & 0 & 0 & 0 & 1 & 0 & $\mathrm{~V}_{\mathrm{A}}$ & $\mathrm{V}_{\mathrm{B}}$ & $\mathrm{V}_{\mathrm{AB}}$ & $\mathrm{i}_{\mathrm{p}}$ & $-\mathrm{i}_{\mathrm{p}}$ & 0 \\
\hline 1 & 0 & 0 & 1 & 0 & 0 & $\mathrm{~V}_{\mathrm{A}}$ & $\mathrm{V}_{\mathrm{A}}$ & 0 & 0 & 0 & 0 \\
\hline 0 & 1 & 0 & 0 & 1 & 0 & $\mathrm{~V}_{\mathrm{B}}$ & $\mathrm{V}_{\mathrm{B}}$ & 0 & 0 & 0 & 0 \\
\hline 0 & 0 & 1 & 0 & 0 & 1 & $\mathrm{~V}_{\mathrm{C}}$ & $\mathrm{V}_{\mathrm{C}}$ & 0 & 0 & 0 & 0 \\
\hline
\end{tabular}

The reference input current space vector is expressed as

$$
\overrightarrow{\imath_{i}}=I_{i} e^{j\left(\omega_{i} t-\varphi_{i}\right)}=I_{i} \angle \theta_{i}
$$

The reference current vector is synthesized into three vectors: $I_{\alpha}, I_{\beta}$ and $I_{0}$

$\overrightarrow{i_{i}}=d_{\alpha} I_{\alpha}+d_{\beta} I_{\beta}$

$d_{\alpha}$ and $d_{\beta}$ are the duty cycles of $I_{\alpha}$ and $I_{\beta}$ within one switching period respectively.

$$
d_{\alpha}=m_{R} \sin \left(\frac{\pi}{3}-\theta_{i}\right)
$$

$d_{\beta}=m_{R} \sin \theta_{i}$

$0 \leq m_{R} \leq 1$

Where, $m_{R}=\frac{I_{i}}{i_{p}}$ is the modulation index of the rectifier.

The duty cycle of the zero vector $I_{0}$ is calculated using $d_{0}=1-d_{\alpha}-d_{\beta}$

Average DC link voltage $V_{p n}$ generated by the CSR is $V_{p n}=\frac{3}{2} V_{i} m_{R} \cos \varphi_{i}$ 
INTERNATIONAL JOURNAL OF INNOVATIVE RESEARCH IN ELECTRICAL, ELECTRONICS, INSTRUMENTATION AND CONTROL ENGINEERING Vol. 3, Issue 2, February 2015

\begin{tabular}{|c|c|c|c|c|c|c|c|}
\hline \multirow{3}{*}{$\begin{array}{l}\text { Rotor } \\
\text { Position }\end{array}$} & \multicolumn{6}{|c|}{ Forward Rotation } & \multirow{3}{*}{ Switches } \\
\hline & \multicolumn{2}{|c|}{$\begin{array}{l}\text { Hall } \\
\text { Output }\end{array}$} & Sensor & \multicolumn{3}{|c|}{ Output Phase } & \\
\hline & $\overline{\mathrm{H} 1}$ & $\mathrm{H} 2$ & $\mathrm{H} 3$ & $\mathrm{~A}$ & $\mathrm{~b}$ & $\mathrm{C}$ & \\
\hline $0-60^{\circ}$ & 1 & 0 & 0 & 1 & 0 & -1 & $S_{L 1}, S_{L 2}$ \\
\hline $60-120^{\circ}$ & 1 & 0 & 1 & 1 & -1 & 0 & $S_{L 1}, S_{L 6}$ \\
\hline $120-180^{\circ}$ & 0 & 0 & 1 & 0 & -1 & 1 & $S_{L 5}, S_{L 6}$ \\
\hline $180-240^{\circ}$ & 0 & 1 & 1 & -1 & 0 & 1 & $S_{L 5}, S_{L 4}$ \\
\hline $240-300^{\circ}$ & 0 & 1 & 0 & -1 & 1 & 0 & $S_{L 3}, S_{L 4}$ \\
\hline $300-360^{\circ}$ & 1 & 1 & 0 & 0 & 1 & -1 & $S_{L 3}, S_{L 2}$ \\
\hline 1410 & & ${ }_{15}[\mathrm{C}$ & $\leqslant 6$ & $16[A B]$ & & & dola \\
\hline
\end{tabular}

Fig. 3 Input Current vector and reference vector

\section{OPERATION OF BLDC MOTOR}

In conventional DC motor, mechanical commutation is achieved using brushes which results in friction, noise, sparks and these drawbacks can be overcome by BLDC motors (BLDCM). The BLDC motor has a permanent magnet in rotor and thewindings are wound in the stator [1]. The motor is supplied by three phase rectangular currentblocks of $120^{\circ}$ duration, in which ideal motional EMF istrapezoidal. In each phase, the flat top of the back EMF is in phase with the conduction period of the phase current to generate the maximum torque. The machine needs rotor positioninformationfor every $60^{\circ}$ electrical and these signals provide the correct commutation information to the logic circuit. Due to this, the BLDC motor rotates continuously.

\section{A SWITCHING STRATEGY}

In the $120^{\circ}$ mode operation of inverter, two switches are turned $\mathrm{ON}$ at a time. Table 2 shows the switching sequence formulation based on the rotor position [18]. The switching sequence can be explained as follows. In Table 2, "1" represents positive excitation, "-1" represents negative excitation and " 0 " represents no current flows through the winding. For the rotor position $\left(0^{\circ}-60^{\circ}\right)$, conducting devices $S_{L 1}$ and $S_{L 2}$ are turned $\mathrm{ON}$ so that winding $\mathrm{C}$ and $\mathrm{A}$ gets energized with positive voltage applied to A phase and negative voltage applied to $\mathrm{C}$ phase.

TABLE 2

SWITCHING SEQUENCE FOR VSI

For the rotor position $60^{\circ}-120^{\circ}$, winding $\mathrm{B}$ (negative voltage) and $\mathrm{A}$ (positive voltage) gets energized with conducting devices $S_{L 1}$ and $S_{L 6}$. This process continues for a full electrical cycle and various switches conduct for various positions. Motor parameters used in this paper is shown in Table.3.
TABLE 3

BLDC MOTOR PARAMETERS

\begin{tabular}{|l|l|}
\hline Motor parameters & Values \\
\hline Stator phase Resistance $(\mathbf{\Omega})$ & 3.07 \\
\hline Stator phase Inductance $(\boldsymbol{m H})$ & 6.75 \\
\hline pole pairs & 2 \\
\hline Torque constant $(\mathbf{N m} / \boldsymbol{A})$ & 0.49 \\
\hline Inertia $\left(\boldsymbol{k g m}^{\mathbf{2}}\right)$ & 0.00018 \\
\hline Friction Factor & 0.005 \\
\hline
\end{tabular}

IV.

OPEN LOOP SYSTEM

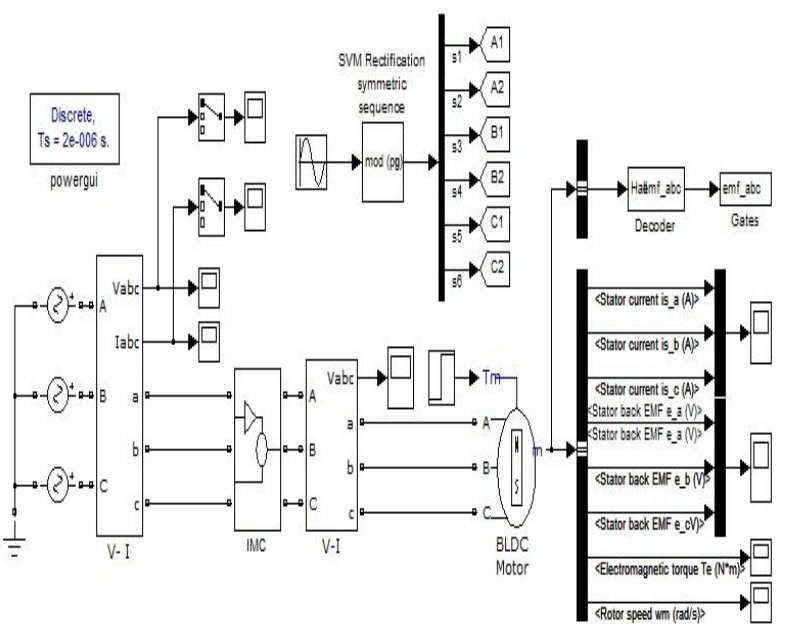

Fig.4. Simulation Diagram of Open loop MC

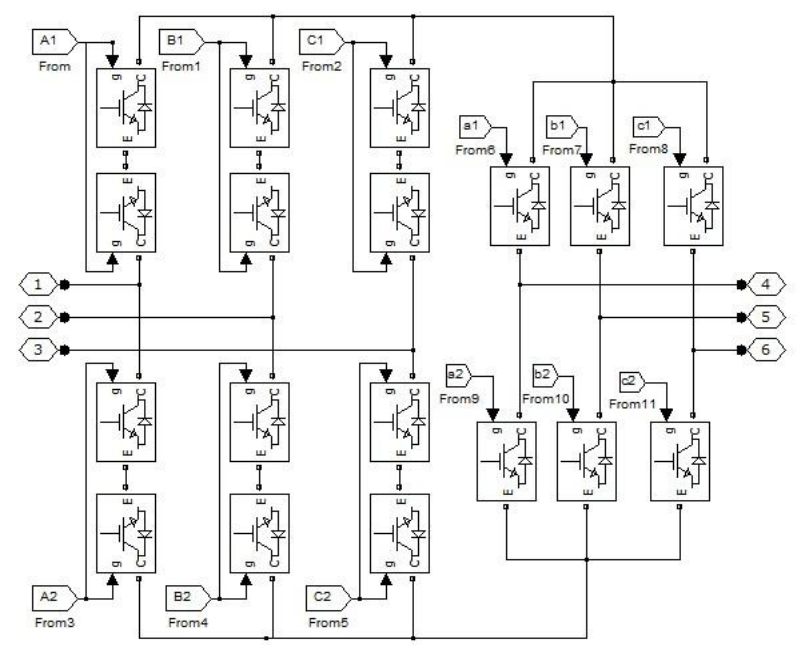

Fig. 4(b).Inside view of Indirect Matrix Converter

Space-vector modulation(SVM)is used to generate the gate pulses for CSR. The inverter gate signals are produced by decoding the Hall effect signals of the BLDC motor and the three-phase output of the converter are applied to the stator windings of BLDC motor. Fig. 4(a) Shows the Matlab / Simulink model of MC fed BLDC motor drive in openloop and Fig. 4(b) shows the inside view of IMC. 


\section{A. $\quad$ Simulation Results and discussions}

The motor is initially started with the no load. The speed of the motor reaches $1000 \mathrm{rpm}$ at $0.01 \mathrm{sec}$. The load torque of $3 \mathrm{Nm}$ is applied to the machine's shaft at $\mathrm{t}=0.1 \mathrm{~s}$ and shown in Fig.5(c).At this point the speed of the motor reduces from $1000 \mathrm{rpm}$ to $800 \mathrm{rpm}$ which is shown in Fig.5(d) and the magnitude of trapezoidal back EMF also reduceswith speed is shown in Fig.5(b). The stator current increases from no load current to $2.5 \mathrm{~A}$ and shown in Fig.5(a).

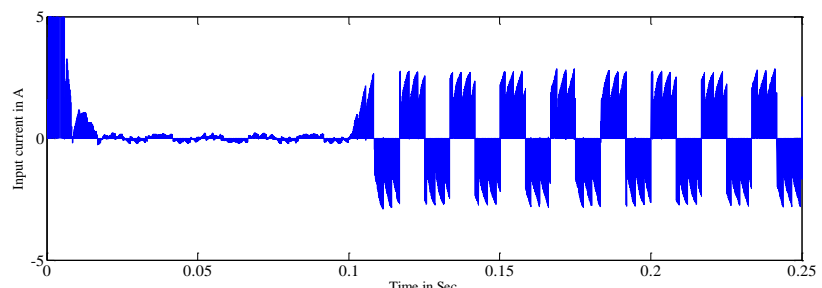

(a)

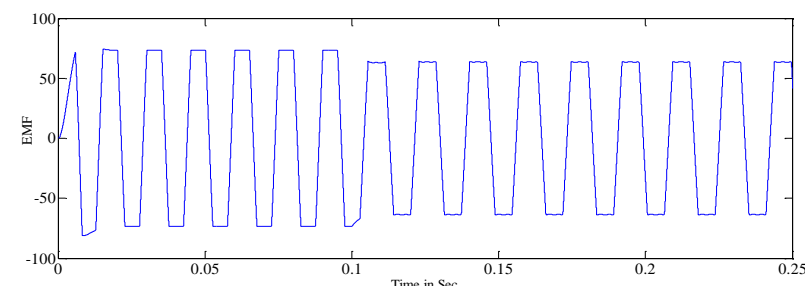

(b)

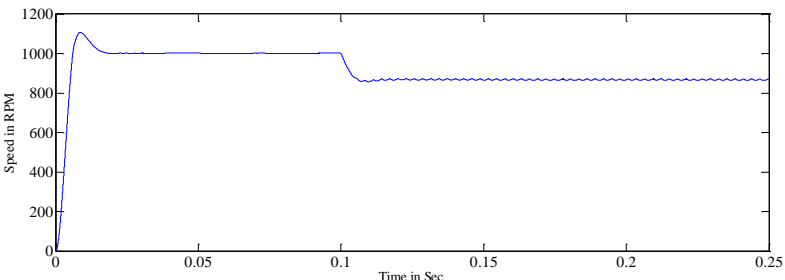

(c)

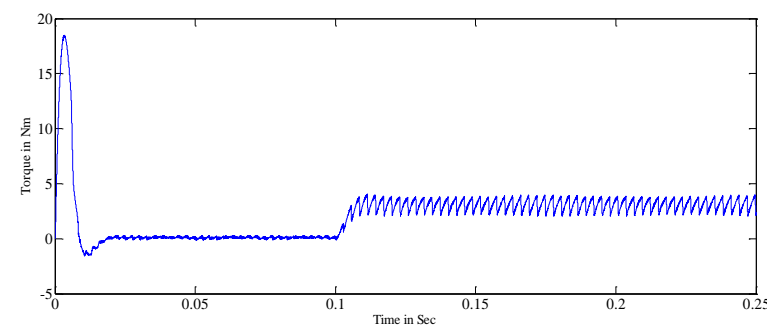

(d)

Fig.5. Simulated Waveforms of open loop a) Stator current b) EMF c)speed d) torque

\section{CLOSED LOOP CONTROL AND SIMULATION RESULTS}

There could be two control loops functioning simultaneously: Inner torque control loop and outer speed control loop. The inner current loop synchronises the inverter gate signals with the electromotive forces. The outer loop controls the speed of the BLDC motor.

In the speed controller, proportional and integral (PI) control action is presented to achieve better speed response and PI current control loop reduces the torque ripple of the BLDC motor. The actual speed is measured and it is compared with the reference speed in the outer speed loop and the error is given to the PI speed
Controller. Hall sensors are used for measuring the actual speed of the motor.This controller generates the reference torque. In BLDC motor, the reference torque is proportional to stator current and the current reference $\left(I_{\text {Ref }}\right)$ is obtained from the speed controller.

$I_{\text {Ref }}=T_{\text {ref }} / K_{t}$

\section{Where $K_{t}$ - Torque constant}

The PWM current controller is used to reduce the torque ripples and the torque reference is decomposed into stator current references and the phase currents of the motor are sensed and compared with the respective phase current references. These current errors are given to PI controller in each phase.

The current controller's output is the reference voltage signal to interact with the PWM carrier signal to generate the gate pulses with variable duty cycle for the devices in the corresponding phase leg of the inverter.In order to achieve optimum solutions for $\mathrm{K}_{p}$ andK $\mathrm{K}_{i}$ gains, manualtuning method is used according to the system characteristics.In this paper, the $\mathrm{K}_{p}$ andK $\mathrm{K}_{i}$ values of speed controller are 0.137 and 1 and for the current controller are 40 and 3 respectively.Fig. 6 shows the block diagram of closed loop system. The simulated diagram of closed loop system is shown in Fig.7. The motor is started at no load with reference speed of $1000 \mathrm{rpm}$ at $0.01 \mathrm{sec}$. At $0.05 \mathrm{sec}$, the reference speed of the motor is increased to $1100 \mathrm{rpm}$ which is shown in Fig.8(b). The motor develops rated torque to bring the motor to the new operating point. The load of $3 \mathrm{Nm}$ is applied at $0.1 \mathrm{~s}$ which is shown in Fig.8(c). At this point the motor draws the required higher current from the supply to meet the requirement of the load torque.

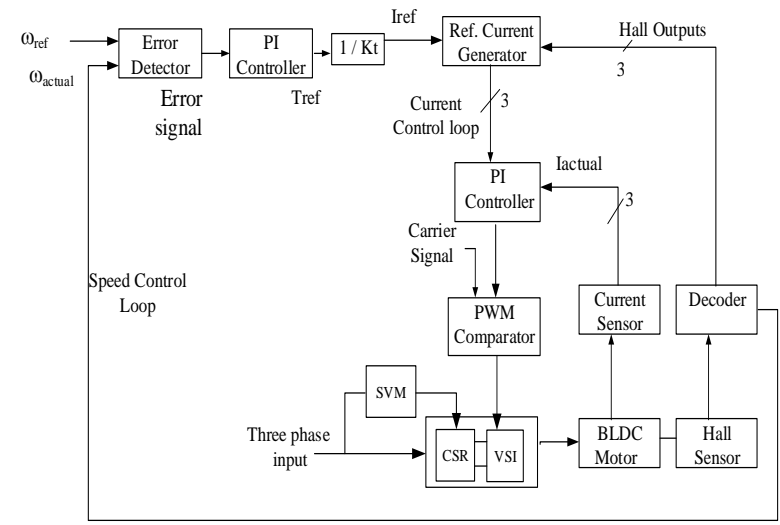

Fig.6. Block Diagram of Closed loop Control

Fig.8(a) shows the input current waveformwhich has reduced harmonic content.In the closed loop system, due to the presence of the current controller, regeneration takes place. Due to that, the current is negative eventhough the emf is positive. 


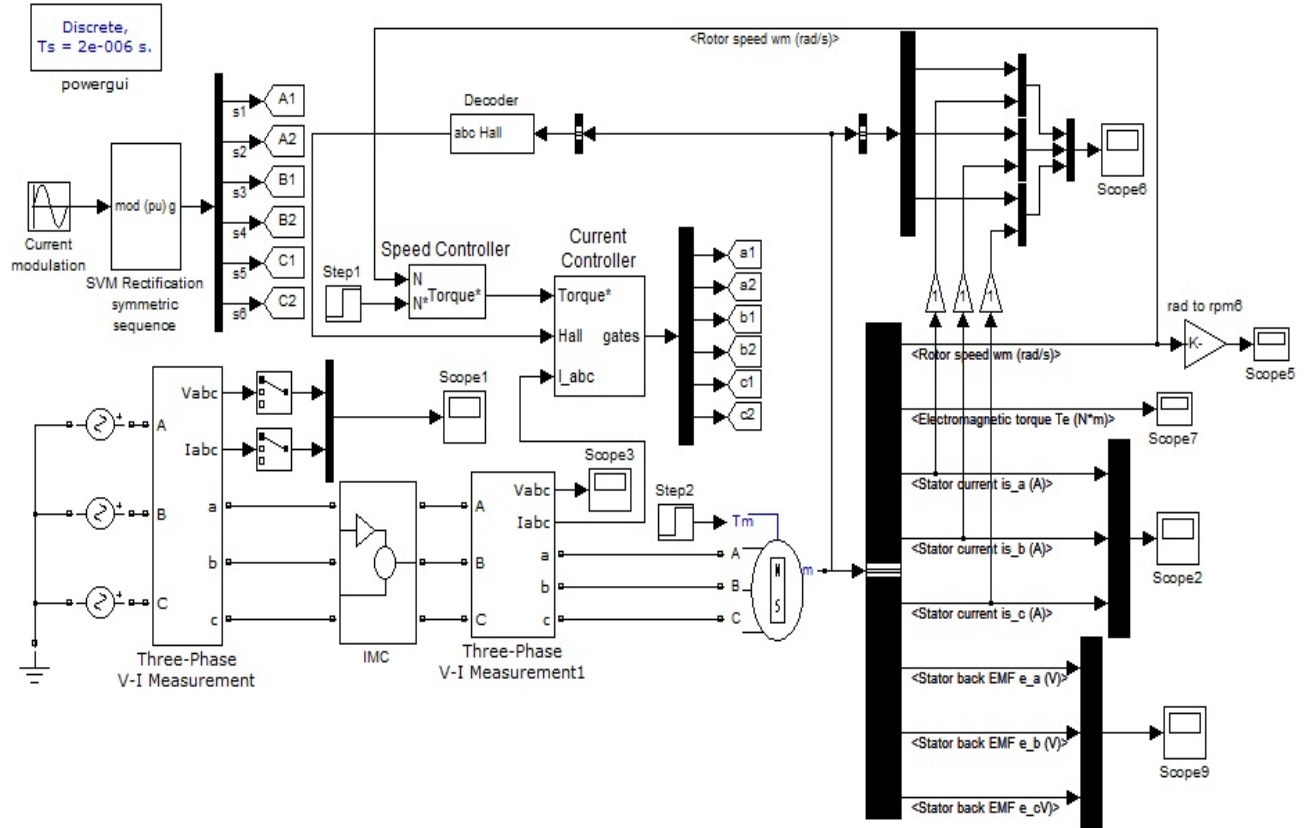

Fig.7.simulated diagram of closed loop system

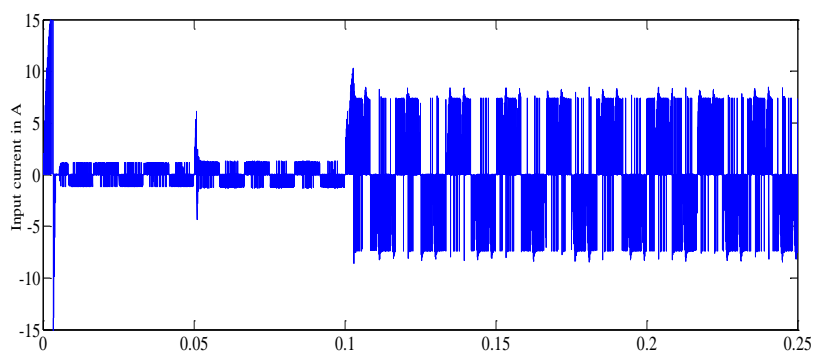

(a)

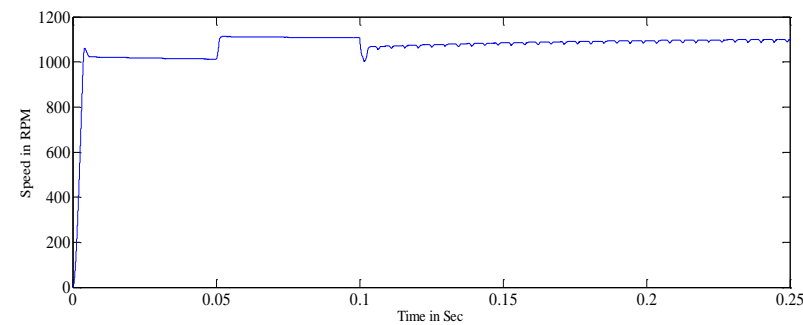

(b)

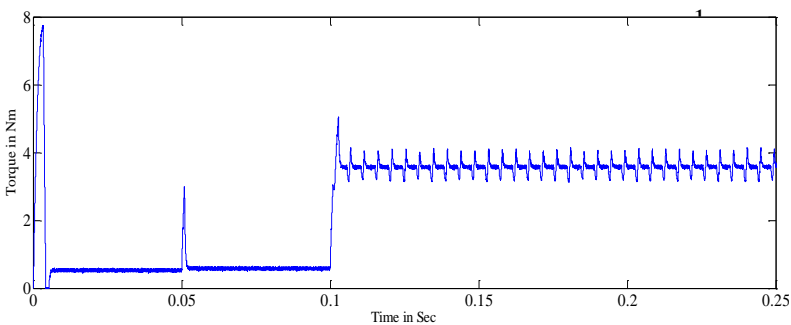

(c)

Fig.8. closed loop simulated waveforms a) Input current b) speed c) torque
VI.

COMPARATIVE ANALYSIS

A. SpeedAnalysis

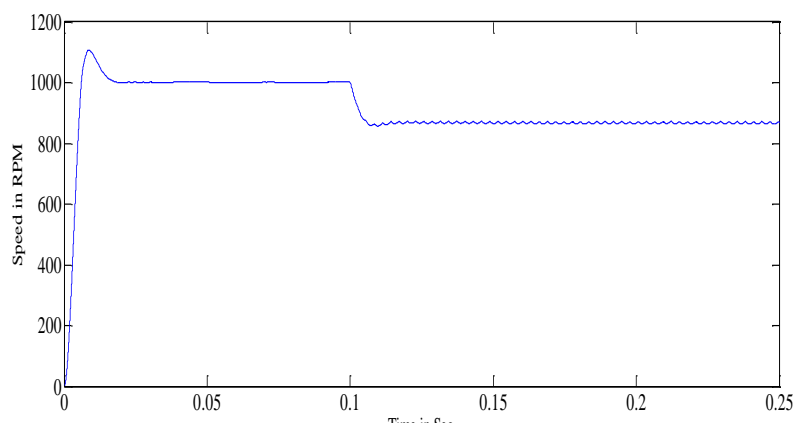

(a)

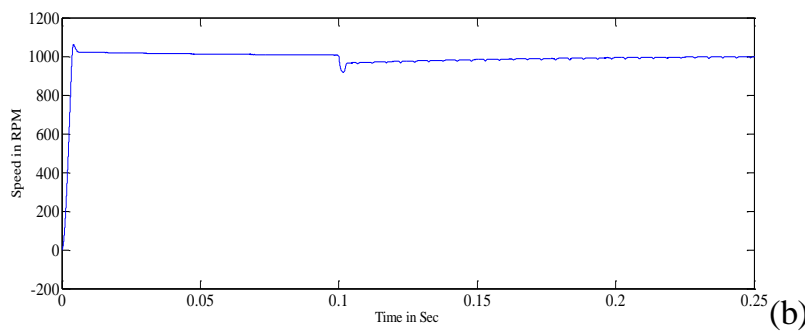

Fig.9. speed response of (a) open loop (b) closed loop control system

Fig.9 (a) \& (b) shows the speed curve of open loop and closed loop control system respectively. In the closed loop system, the speed of $1000 \mathrm{rpm}$ is maintained as constant after the load of $3 \mathrm{Nm}$ whereas in the openloop, the speed is reduced from 1000rpm to $800 \mathrm{rpm}$.

\section{B. Torque Analysis}

Figure 10 (a) \& (b) shows the load torque of open loop and closed loop respectively. The torque in open loop lies in the range between 2-4 $\mathrm{Nm}$. In the closed loop control, PI current controller reduces the torque ripples and the torque lies in the range between $3.32-3.85 \mathrm{Nm}$. For the load torque of $3 \mathrm{Nm}$, the torque is $2 \mathrm{Nm}$ in open loop 
INTERNATIONAL JOURNAL OF INNOVATIVE RESEARCH IN ELECTRICAL, ELECTRONICS, INSTRUMENTATION AND CONTROL ENGINEERING Vol. 3, Issue 2, February 2015

system whereas $0.5 \mathrm{Nm}$ in the closed loop system.Comparison of speed and torque between open loop and closed loop system is shown in Table 4.

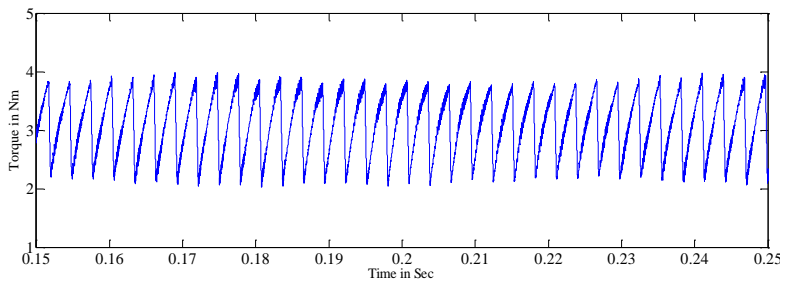

(a)

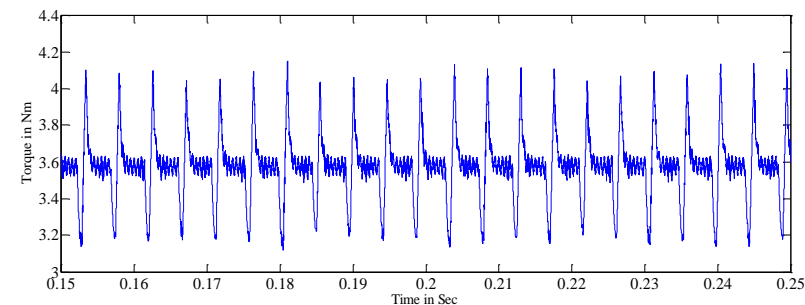

(b)

C.

Input Current Analysis

Figure 4.11 (a) \& (b) shows the input current of open loop and closed loop control system respectively.

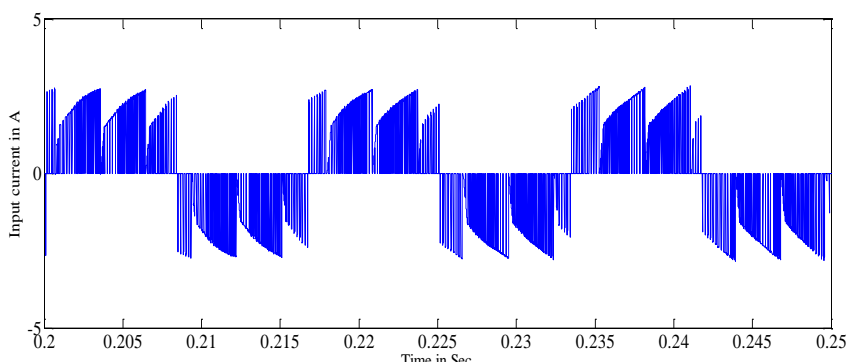

(a)

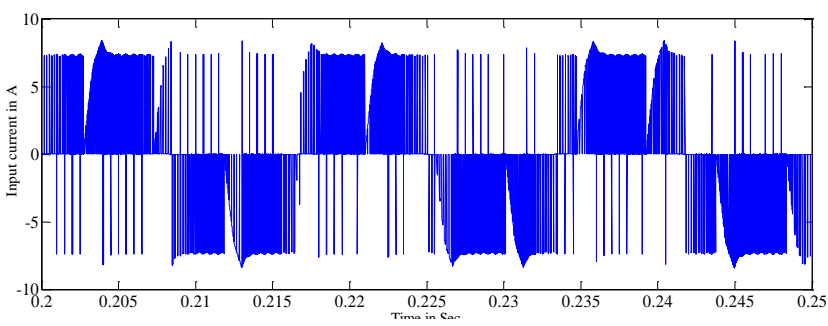

(b)

Fig. 11. Input current in (a) Open loop system, (b) Closed loop control system

In the open loop system, the current is positive when the emf is positive and the current is negative when the emf is negative and produces the unidirectional torque. When the load torque is $3 \mathrm{Nm}$, the speed of the motor is $800 \mathrm{rpm}$ and the input current is $2.8 \mathrm{~A}$.

In the closed loop system, due to the presence of the current controller, regeneration takes place. Due to that, the current is negative eventhough the emf is positive. When the load torque is $3 \mathrm{Nm}$, the speed of the motor is $1000 \mathrm{rpm}$ and the input current is $6.2 \mathrm{~A}$.
TABLE 4

COMPARISON BETWEEN OPEN LOOP AND CLOSED LOOP SYSTEM

\begin{tabular}{|l|l|l|l|l|}
\hline \multirow{2}{*}{} & \multicolumn{2}{|l|}{ OPEN LOOP } & \multicolumn{2}{l|}{$\begin{array}{l}\text { CLOSED } \\
\text { LOOP }\end{array}$} \\
\cline { 2 - 5 } & $\begin{array}{c}\text { No } \\
\text { load }\end{array}$ & $\begin{array}{c}\text { 3Nm } \\
\text { load }\end{array}$ & $\begin{array}{l}\text { No } \\
\text { load }\end{array}$ & $\begin{array}{l}\text { 3Nm } \\
\text { Load }\end{array}$ \\
\hline Speed (RPM) & 1000 & 800 & 1000 & 1000 \\
\hline Torque (Nm) & 0.2 & 2 & $\begin{array}{l}0.26- \\
0.36\end{array}$ & 0.5 \\
\hline
\end{tabular}

\section{CONCLUSION}

In this project, torque ripple minimization of IMC fed BLDC motor and proper switching of the IMC has been presented and simulated using MATLAB/SIMULINK. SVM technique is used to reduce the harmonic contents and it maintains sinusoidal input current. It can be concluded that the closed loop drive with PI controller offers reduced torque ripple to modulate the matrix converter for driving BLDC motors with reduced supply harmonics when compared with the openloop system.

\section{REFERENCES}

[1] R. Krishnan and Shiyoung, L., PM brushless DC motor drive with a new power-converter topology, IEEE Tran. Indus. Appl., Vol. 33, No. 4, 973-982, 1997

[2] R. Krishnan, " A Text Book on Electric Motor Drives, Modelling, Analysis and Control", Prentice Hall of India Pvt Ltd., New Delhi., 2003.

[3] Jiancheng Fang, Xinxiu Zhou, gang Liu," Instantaneous Torque Control of Small Inductance Brushless DC Motor', IEEE Transactions on Power Electronics, Vol. 27, No.12, pp. 49524964, Dec. 2012.

[4] F Aghili, "Fault Tolerant Torque control of BLDC motors", IEEE Transactions on Power Electronics, Vol. 26, No.2, pp. 355-363, Nov. 2011.

[5] Y.S.Lai , Y.S.Lin, "A unified Approach to Zero crossing point detection of back EMF for Brushless DC motor drives without current and hall Sensors", IEEE Transactions on Power Electronics, Vol. 26, No.6, pp. 1704-1713, June. 2011.

[6] Viswanathan, Jeevanantham, "A Novel current controlled Space vector modulation based Control Scheme for Reducing Torque Ripple in Brushless DC Drives", International Journal of Computer applications, Vol.28, No.2, pp.25-31, August. 2011.

[7] Chang Liang Xia, Permanent Magnet Brushless DC Motor Drives and Controls, Wiley Press, Beijing, 2012.

[8] G.R.A Markadeh , S. I. Mousavi , Daryabeigi(2008)., ' Position sensorless direct torque control of BLDC motor by using modifier,' Optimization of Electrical and Electronic Equipment,. OPTIM 2008., 11th International Conference., 93 - 99, 2008.

[9] Bharani Kumar and Nirmal Kumar, "Performance Analysis of wind Turbine -driven permanent magnet generator with matrix converter", Turk J Elec Eng\& Comp Sci, Vol. 20, No.3, pp.299-317, 2012.

[10] Tiangui Jiang, Bozhou, Chumei Hong, Mingmingshi, "New Modulation Scheme for matrix converter driving BLDC Motor", International Conference on Electrical machines and systems, pp.1445-1450, Oct. 2008

[11] L.Huber and D.Borojevic, "Space vector modulated Three-phase to Three phase Matrix converter with Input power factor correction," IEEE Trans. Ind. Appl., Vol 31, No.6, pp.1234-1246, Nov,1995.

[12] M. Imayavaramban, A.V. Krishnachaithanya, and B. G. Fernandes, "Analysis and Mathematical Modelling of Matrix Converter for adjustable speed AC Drives", Power System Conference and Exposition, PSCE'06,pp. 1113-1120, 2006.

[13] A. Alesina, M. Venturini (1989), 'Analysis and design of optimum -design ofnine switch direct AC-AC converter', IEEE trans Power Electron Vol 4, pp. 101-112.

[14] Thomas Freidli., Johann W. Kolar, "Milestones in Matrix converter research," IEEJ Journal of industry applications, vol 1,No 1,pp 214,March 2012

[15] L.Huber , D. Borojevic , N. Burany , ' Voltage space vector based PWM control of forced commutated cycloconverter', 
Proceeding of industrial electronics society annual conference, vol 1, 106-111, 1989.

[16] P.D.Ziogas, Y.G.Kang, and V.R.Stefanovic,'Rectifier-Inverter Frequency changers with suppressed DC link components,"IEEE Trans. Ind. Appl., Vol. 22, No. 6, pp. 1027-1036, Nov 1986.

[17] S. Kim, S.K.Sul, and T.A.Lipo, "AC to AC power conversion Based on Matrix Converter Topology with Unidirectional Switches," in Proc. 13 ${ }^{\text {th }}$ IEEE APEC, Vol. 1, pp.301-307, Feb. 1998.

[18] T.J.E. Miller, "Brushless permanent-Magnet and Reluctance Motor Drives",Clarendon Press Oxford.

[19] J.Rodriguez (1983), 'A new control technique for AC-AC converter',Proceedings of control of power electronics andelectrical drive conference, pp.203-208.

[20] J.Karpagam, A.N.Kumar,V.Kumar,"Comparison of Modulation Techniques for Matrix Converter", IACSIT Int J of Engg \& Tech, vol.2,No.2, pp.189-195, April. 2010. 